\title{
Differential effects of basolateral and apical iron supply on iron transport in Caco-2 cells
}

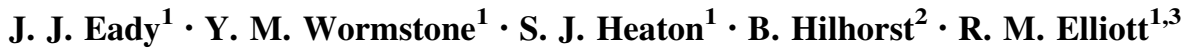

Received: 11 November 2014/Accepted: 8 April 2015/Published online: 22 April 2015

(C) Springer-Verlag Berlin Heidelberg 2015

\begin{abstract}
Iron homeostasis in the human body is maintained primarily through regulation of iron absorption in the duodenum. The liver peptide hepcidin plays a central role in this regulation. Additionally, expression and functional control of certain components of the cellular iron transport machinery can be influenced directly by the iron status of enterocytes. The significance of this modulation, relative to the effects of hepcidin, and the comparative effects of iron obtained directly from the diet and/or via the bloodstream are not clear. The studies described here were performed using Caco-2 cell monolayers as a model of intestinal epithelium, to compare the effects of iron supplied in physiologically relevant forms to either the apical or basolateral surfaces of the cells. Both sources of iron provoked increased cellular ferritin content, indicating iron uptake from both sides of the cells. Supply of basolateral transferrin-bound iron did not affect subsequent iron transport across the apical surface, but reduced iron transport across the basolateral membrane. In contrast, the apical iron supply led to subsequent reduction in iron
\end{abstract}

Electronic supplementary material The online version of this article (doi:10.1007/s12263-015-0463-5) contains supplementary material, which is available to authorized users.

R. M. Elliott

r.m.elliott@surrey.ac.uk

1 Institute of Food Research, Norwich Research Park, Colney, Norwich NR4 7UA, UK

2 Nutrition, Metabolism and Genomics Group, Division of Nutrition, Wageningen University, Wageningen, The Netherlands

3 Department of Nutritional Sciences, School of Biosciences and Medicine, Faculty of Health and Medical Sciences, University of Surrey, Guildford GU2 7XH, UK transport across the apical cell membrane without altering iron export across the basolateral membrane. The apical and basolateral iron supplies also elicited distinct effects on the expression and subcellular distribution of iron transporters. These data suggest that, in addition to the effects of cellular iron status on the expression of iron transporter genes, different modes and direction of iron supply to enterocytes can elicit distinct functional effects on iron transport.

Keywords Iron uptake · Iron transport · Iron metabolism · Iron homeostasis - Gene expression · Intestinal epithelium

\section{Introduction}

Iron is an essential component for many cellular processes including oxygen transport, energy production and numerous enzymatic reactions. Commonly, iron functions as an electron acceptor/donor through its capacity to convert between the ferric and ferrous forms. However, this same property makes excess iron toxic, with free iron having the potential to elicit severe oxidative stress (Kruszewski 2003). Thus, tight regulation of iron homeostasis with appropriate storage of body iron is vital for maintenance of health.

Since humans lack a defined regulated mechanism for active iron excretion, homeostasis is sustained primarily through regulation of intestinal iron absorption from the diet (Frazer and Anderson 2005). As crypt cells migrate to the villi of the intestinal epithelium, they differentiate into mature absorptive enterocytes (King et al. 1981). In the duodenum, this differentiation process includes the coordinated activation of the cellular machinery for absorption 
of iron from dietary sources and for iron transport into the bloodstream; increasing expression of the genes that form the individual components of the iron transport system including the ferric reductase duodenal cytochrome $b$ reductase 1, divalent metal ion transporter 1 (DMT-1), ferroportin (FPN) and hephaestin (Canonne-Hergaux et al. 1999; Donovan et al. 2000; Vulpe et al. 1999). The expression of these genes and the activity of their products are regulated also by body iron status/demand as well as by dietary iron supply (Canonne-Hergaux et al. 1999; Collins et al. 2005; Frazer et al. 2003; Gunshin et al. 1997, 2001; Millard et al. 2004). This indicates that the intestinal epithelium possesses mechanisms for sensing whole-body iron requirements and it has been widely postulated that feedback control of iron absorption by the intestinal epithelium is achieved via signalling molecules present in plasma: the so-called stores regulator and erythropoietic regulator (Roy and Enns 2000).

Ferritin, transferrin (Tf) and serum Tf receptor have all been put forward previously as possible candidates for the stores regulator (Roy and Enns 2000). However, the liver peptide hepcidin is now widely accepted as the main stores regulator (Frazer and Anderson 2005; Ganz and Nemeth 2006). Expression and secretion of hepcidin from the liver is regulated by iron status and inflammation (Mazur et al. 2003; Nemeth et al. 2004a; Nicolas et al. 2002). Hepcidin acts as a negative regulator of iron absorption by binding to and promoting the internalisation and degradation of FPN, the iron transporter present on the basolateral membrane of enterocytes that is responsible for exporting iron from the epithelium into the blood stream (Nemeth et al. 2004b). Additionally, there is some evidence that hepcidin also may act to suppress iron absorption at the apical surface of the enterocytes (Brasse-Lagnel et al. 2011; Mena et al. 2008; Yamaji et al. 2004).

However, a model for regulation of intestinal iron transport that involves hepcidin alone does not take into account other feedback control mechanisms that regulate iron homeostasis at the cellular, rather than whole body, level. Such mechanisms include the extensively characterised iron response protein (IRP)-iron response element (IRE) interactions, which act in an iron-sensitive manner at a post-transcriptional level to regulate expression of a number of the key genes involved in iron transport and cellular homeostasis (Lymboussaki et al. 2003; Menotti et al. 1998; Pantopoulos 2004). Additionally, some of these same genes, as well as genes that do not contain an IRE, may also be regulated in an iron-sensitive manner yet to be fully defined, which is independent of the IRP-IRE system (Han et al. 1999; Zoller et al. 2002). Intestinal epithelial cells are uniquely placed in this context since they can derive cellular iron both from the bloodstream, as for other tissues, and directly from dietary sources. Thus, both sources have the potential to affect enterocyte iron status. Moreover, enterocytes need to strike a constant balance between maintaining an appropriate supply of iron to meet the demands of the rest of the body while also ensuring adequate and appropriate iron supply for their own requirements.

The studies described here were performed to test the hypothesis that, in addition to other somatic signals such as hepcidin, the supply of iron to enterocytes from the diet and the body contributes to the regulation of dietary iron absorption by influencing crypt cell and/or mature villus enterocyte iron status. The Caco- 2 model of intestinal epithelium was employed to compare effects of ferric nitrilotriacetate (NTA), supplied to the apical surface of the cells to mimic dietary iron, or Tf-bound iron, supplied to the basolateral surface of the cells to mimic somatic iron, on the iron transport capacity of the cells and on the expression of iron transport machinery. The experiments were performed using cells grown on permeable supports in bicameral chambers during the process of cellular differentiation that occurs subsequent to the cells growing to confluence. These conditions were selected for the investigations since the differentiation process for Caco- 2 cells shares many common themes with the changes that occur during the differentiation of crypt cells into mature absorptive enterocytes, including the coordinated up-regulation of the cellular iron transport machinery (BedrineFerran et al. 2004; Fleet et al. 2003; Han et al. 1999; Sharp et al. 2002). Numerous previous studies have demonstrated that prior loading of Caco- 2 cells with free iron, supplied to both the apical and basolateral sides of the cells, can affect subsequent iron uptake and transport (Arredondo et al. 1997; Sharp et al. 2002; Tallkvist et al. 2003). However, to our knowledge, this is the first study comparing the effects of supply of iron to Caco- 2 cells specifically via apical or basolateral surfaces and in forms representative of those enterocytes would be exposed to in vivo.

\section{Materials and methods}

\section{Cell culture conditions}

Caco- 2 cells were obtained from the American Type Culture Collection (Rockville, MD, USA) and used in all the experiments described here between passages 26 and 31 . Cells were routinely cultured at $37{ }^{\circ} \mathrm{C}$ in an incubator with a $5 \% \mathrm{CO}_{2}, 95 \%$ air atmosphere at constant humidity in Dulbecco's Modified Eagle Medium (DMEM) containing $10 \%(\mathrm{v} / \mathrm{v})$ foetal bovine serum (FBS), 100 units/ml penicillin, $100 \mathrm{mg} / \mathrm{ml}$ streptomycin, $2 \mathrm{mM} \mathrm{L-glutamine}$ and $1 \%$ (v/v) non-essential amino acid solution (Sigma Aldrich, Poole, UK). The culture medium was refreshed 
every 2-3 days, and cells passaged every 7 days. Iron-depleted FBS was prepared by treating FBS with Chelex ${ }^{\circledR} 100$ chelating ion exchange resin (Bio-Rad, Hemel Hempstead, UK) as described previously (Alvarez-Hernandez et al. 1991). The iron concentration in the FBS prior to, and following, Chelex ${ }^{\circledR} 100$ treatment was determined by atomic absorption spectrophotometry using a Perkin-Elmer Atomic Absorption Spectrophotometer Model 3300 (Fernandez and Kahn 1971).

For all experiments, cells were seeded at a density of 30,000 cells $/ \mathrm{cm}^{2}$ in 6- or 12-well Transwell ${ }^{\circledR}$ permeable support plates $\left(\right.$ Costar $^{\circledR}$, Corning Inc., New York, USA). The medium was refreshed every $2-3$ days. Transepithelial electrical resistance (TEER) was monitored, using an EVOM2 Epithelial Voltohmmeter (World Precision Instruments, Hitchin, UK), over subsequent days to confirm time to confluence and the permeability of the cell monolayers prior to experimental manipulations. On day 14 after seeding, the cells were transferred to medium containing the metal-depleted FBS at $10 \%$ v/v both above and below the cells. To one set of the Transwells, 30- $\mu \mathrm{M}$ human ironsaturated Tf (holo-Tf from Sigma, Poole, UK) was added to the basolateral medium. To another set, $10 \mu \mathrm{M}$ ferric NTA was added to the apical medium. For controls, no additional source of iron was added. The media preparations were refreshed every 2-3 days for 1 week prior to performing ferritin, iron transport, mRNA and protein expression analyses on day 21 .

\section{Ferritin analysis}

Ferritin concentrations in cell lysates were determined by enzymatic immunoassay using the Ramco Laboratories Spectro-Ferritin kit S-22 (ATI Atlas, Chichester, UK) according to the manufacturer's instructions. Ferritin concentrations in the lysates were normalised against total protein content determined using the Micro-BCA protein assay kit (Fisher Scientific UK Ltd, Loughborough, UK).

\section{Iron uptake and transport analysis}

For analysis of iron uptake and transport, the culture medium was removed and the cells washed with Hanks' buffered salt solution (HBSS from Sigma, Poole, UK). Transepithelial $\mathrm{pH}$ gradients were established essentially as described by Tandy et al. (2000), by adding HBSS (pH 7.4) to the basolateral chamber and PIPES buffered salt solution (identical in composition to HBSS except that the HEPES was replaced with PIPES and the $\mathrm{pH}$ adjusted to 6.5) to the apical chamber. Uptake was initiated by the addition to the apical chamber of $10 \mu \mathrm{M}$ ferric NTA, containing sufficient ${ }^{55} \mathrm{Fe}$ to give a final activity of $37 \mathrm{kBq} / \mathrm{ml}$. The cells were placed in an incubator at $37{ }^{\circ} \mathrm{C}$ on an orbital shaker rotating at $\leq 80 \mathrm{rpm}$. After $2 \mathrm{~h}$, the apical and basolateral media were removed to separate tubes. The apical surface of the cells was washed twice with ice-cold HBSS, and the wash solutions were pooled with the corresponding apical medium solutions. The apical surface of the cells was washed for a further $10 \mathrm{~min}$ with ice-cold $140 \mathrm{mM} \mathrm{NaCl}$, $5 \mathrm{mM} \mathrm{KCl}, 10 \mathrm{mM}$ PIPES, containing $5 \mathrm{mM}$ sodium dithionite and $1 \mathrm{mM}$ bathophenanthroline disulphonic acid to ensure removal of any non-specifically bound surface iron (Glahn et al. 1995). This wash solution was removed and combined with the apical media and previous washes. The cells were lysed with $0.2 \mathrm{M} \mathrm{NaOH}$, and the lysates neutralised with an equal volume of $0.2 \mathrm{M} \mathrm{HCl}$. Portions of the apical medium (including wash solutions), basolateral medium and cell lysates were subjected to scintillation counting.

\section{Real-time RT-qPCR analysis}

Prior to isolation of RNA, medium was removed from the Transwells and the cells were washed with HBSS. RNA isolation was performed using RNeasy Mini kits (Qiagen, Crawley, UK) according to the manufacturer's instructions and stored at $-80^{\circ} \mathrm{C}$. Total RNA yield was determined using a NanoDrop ${ }^{\circledR}$ ND-1000 spectrophotometer (NanoDrop Technologies, Wilmington, USA) and RNA purity assessed by the ratio of absorbance at 260 and $280 \mathrm{~nm}$. All samples had 260/280 absorbance ratios greater than 1.8. Total RNA integrity was assessed using Agilent RNA6000nano LabChips ${ }^{\circledR}$ (Agilent Technology 2100 Bioanalyzer Version A.01.20 SI211). All samples had RIN scores greater than 8 .

Real-time RT-qPCR was performed using an ABI Prism 7300 or 7700 Sequence Detection System (Applied Biosystems) for each of three test genes (transferrin receptor-1 (TfR-1), DMT-1 and FPN) plus the reference gene RNA polymerase 2 polypeptide A (POLR2A) (Radonic et al. 2004). The primers and probes used for POL2RA were as described previously (Hurst et al. 2008). Primers and probes the other genes were designed using Primer Express Software (Applied Biosystems) with all amplicons designed to span intron-exon boundaries (Table 1). Sequence homology of selected oligomers was checked by NCBI BLAST search to ensure sequences were specific to target genes. The probes were labelled with a $5^{\prime}$ reporter dye, FAM (6-carboxyfluorescein) and $3^{\prime}$ quencher dye, TAMRA (6-carboxytetramethylrhodamine). A one-step RT-qPCR was employed for all assays. Real-time RT-qPCRs were carried out in 96-well plates using Taqman ${ }^{\circledR} 1$-step RTPCR master mix reagent kits (Life Technologies, Paisley, UK) in a total volume of 
Table 1 Real-time RT-qPCR primer and probe sequences, amplicon lengths and mRNA variants amplified

\begin{tabular}{|c|c|}
\hline \multicolumn{2}{|l|}{ Gene } \\
\hline \multicolumn{2}{|l|}{ POLR2A } \\
\hline Forward primer & $5^{\prime}$ GCAAATTCACCAAGAGAGACG $3^{\prime}$ \\
\hline Reverse primer & $5^{\prime}$ CACGTCGACAGGAACATCAG 3' \\
\hline Probe & $5^{\prime}[\mathrm{FAM}] \mathrm{CCTGGAGC}[\mathrm{TAMRA}] 3^{\prime}$ \\
\hline Amplicon length & 73 nucleotides \\
\hline $\begin{array}{l}\text { mRNA variants } \\
\text { amplified }\end{array}$ & NM_000937.4 \\
\hline \multicolumn{2}{|l|}{ DMT-1 (SLC11A2) } \\
\hline Forward primer & $5^{\prime}$ GATGTAGAGCATCTAACAGGGATGAA $3^{\prime}$ \\
\hline Reverse primer & 5' CCATTGGCAAAGTCACTCATTACT $3^{\prime}$ \\
\hline Probe & $5^{\prime}$ [FAM]TCTACAGAGCTTACAGCTTCCCTTTGCTCT[TAMRA] 3' \\
\hline Amplicon length & 128 nucleotides \\
\hline $\begin{array}{l}\text { mRNA variants } \\
\text { amplified }\end{array}$ & $\begin{array}{l}\text { NM_001174125.1, NM_001174126.1, NM_001174127.1, NM_000617.2, NM_001174128.1, NM_001174129.1, } \\
\text { NM_001174130.1 }\end{array}$ \\
\hline \multicolumn{2}{|l|}{ FPN (SLC40A1) } \\
\hline Forward primer & $5^{\prime}$ GCCCATAATCTCTGTCAGTCTGC $3^{\prime}$ \\
\hline Reverse primer & $5^{\prime}$ TGCCTCTTTCAGATTCAATTACATTT $3^{\prime}$ \\
\hline Probe & $5^{\prime}$ [FAM]AATCAAAGGACCAAAGACCGATTCTAGCA[TAMRA] 3' \\
\hline Amplicon length & 122 nucleotides \\
\hline $\begin{array}{l}\text { mRNA variants } \\
\text { amplified }\end{array}$ & XM_005246504.1, XM_005246505.1 \\
\hline \multicolumn{2}{|l|}{ TfR-1 (TFRC) } \\
\hline Forward primer & 5' GCTTTCCCTTTCCTTGCATATTCT $3^{\prime}$ \\
\hline Reverse primer & 5' GGTGGTACCCAAATAAGGATAATCTG $3^{\prime}$ \\
\hline Probe & $5^{\prime}$ [FAM]ATCCCAGCAGTTTCTTTCTGTTTTTGCGA[TAMRA] 3' \\
\hline Amplicon length & 87 nucleotides \\
\hline $\begin{array}{l}\text { mRNA variants } \\
\text { amplified }\end{array}$ & NM_001128148.1, NM_003234.2 \\
\hline
\end{tabular}

$25 \mu \mathrm{l} /$ well with a final concentration of $100 \mathrm{nM}$ of the probe and $200 \mathrm{nM}$ of each of the forward and reverse primers. Test samples (10 ng of total RNA per reaction) were analysed by comparison with a standard curve, included on each plate, consisting of serial dilutions (80, 40, 20, 10 and $5 \mathrm{ng} /$ well) of a pooled Caco-2 RNA reference sample. The real-time PCR conditions were as follows: $48{ }^{\circ} \mathrm{C}$ for $30 \mathrm{~min}$, then $95{ }^{\circ} \mathrm{C}$ for $10 \mathrm{~min}$, followed by 40 amplification cycles of $95^{\circ} \mathrm{C}$ for $15 \mathrm{~s}$ and $60{ }^{\circ} \mathrm{C}$ for 1 min. The data generated were analysed with ABI Taqman software. The $r^{2}$ value for log-linear fit of standard curves was $>0.99$ in all cases, and the mean efficiency of amplification (based on the mean gradient of standard curves from four plates for each assay) was 91, 97, 94 and $97 \%$ for POL2RA, DMT-1, FPN and TfR-1, respectively. Performance of each assay was tested to confirm noninterference of human genomic DNA. Within plate intraassay variation, based on the average coefficient of variation for the triplicate analyses of a quality control sample included on each plate, ranged from 4 to $6 \%$ for the genes analysed. Between plate coefficients of variation for the quality control sample ranged from 2 to $11 \%$. The calculated expression values for each gene of interest within each sample analysed were normalised first against the corresponding expression values for the reference gene (POLR2A) for each sample and then against the mean normalised expression level for the control group.

\section{Microarray analysis}

Biotin-labelled cDNA was prepared from RNA samples (five samples for each treatment) using the GeneChip Expression 3' Amplification OneCycle Target labelling kit (Affymetrix). Each cDNA sample was hybridised to a separate Affymetrix human GeneChip ${ }^{\circledR}$ array custom made for NuGO (www.nugo.org) by ServiceXS (Leiden, Netherlands) using the manufacturer's standard protocols. The experimental details and array data are available in MIAME-compliant format from the ArrayExpress database (accession number E-MTAB-3442). 


\section{Preparation of whole-cell and cell-surface-enriched protein extracts}

On day 21, after the different experimental treatments, the medium was removed from the Transwells and the Caco-2 monolayers were washed briefly twice with ice-cold phosphate-buffered saline solution (PBS). Sulfo-NHS-biotin (Thermo Scientific, Loughborough, UK) at a concentration of $0.25 \mathrm{mg} / \mathrm{ml}$ in ice-cold PBS was added to the Transwells and the plates gently agitated at $4{ }^{\circ} \mathrm{C}$ for $30 \mathrm{~min}$. The solution was removed and the cells washed twice with PBS. A solution of $50 \mathrm{mM}$ iodoacetamide in PBS was added to the Transwells to quench any remaining biotinylation reagent activity. The cells were washed twice with PBS and then lysed with ice-cold RIPA buffer (25 mM Tris- $\mathrm{HCl}$ (pH 7.6), $150 \mathrm{mM} \mathrm{NaCl}, 1 \%$ v/v NP$40,1 \% \mathrm{w} / \mathrm{v}$ sodium deoxycholate, $0.1 \% \mathrm{w} / \mathrm{v}$ SDS) containing Halt protease \& phosphatase inhibitor cocktail (both from Thermo Scientific, Loughborough, UK). The cell monolayers were disrupted by scraping, and the cell suspensions were sonicated. The lysates were centrifuged at $12,000 \mathrm{~g}$ for $10 \mathrm{~min}$ at $4{ }^{\circ} \mathrm{C}$, and the supernatant stored in aliquots at $-80{ }^{\circ} \mathrm{C}$. The protein concentration of the extracts was determined using the Micro-BCA kit (Thermo Scientific, Loughborough, UK) according to the manufacturer's instructions.

For the preparation of fractions enriched for biotinylated proteins, $2.5 \mathrm{ml}$ of streptavidin agarose suspension (Sigma, Poole, UK) was washed three times with PBS, centrifuging at $16,200 \mathrm{~g}$ for $2 \mathrm{~min}$ between each wash to sediment the agarose and allow for removal of the PBS wash. The agarose was finally resuspended in PBS to a final total volume of $2 \mathrm{ml}$. Aliquots of the protein extracts $(500 \mu \mathrm{g}$ each) were diluted to $1 \mu \mathrm{g} / \mu \mathrm{l}$ with RIPA buffer. Streptavidin agarose suspension $(80 \mu \mathrm{l})$ was added to each extract and incubated overnight at $4{ }^{\circ} \mathrm{C}$ on a rotating shaker. The samples were centrifuged at $16,200 \mathrm{~g}, 4^{\circ} \mathrm{C}$ for $2 \mathrm{~min}$, and the supernatant was discarded. The agarose was washed three times with ice-cold PBS. After the final wash, the beads were suspended in $50 \mu \mathrm{l}$ LDS sample buffer (prepared by mixing $200 \mu \mathrm{l}$ of $4 \times$ NuPAGE LDS stock solution, $40 \mu \mathrm{l}$ NuPAGE reducing agent (both from Life Technologies, Paisley, UK) and ultrapure water at a ratio of 5:1:14). The solutions were heated at $90{ }^{\circ} \mathrm{C}$ for $10 \mathrm{~min}$ then immediately centrifuged at $16,200 \mathrm{~g}$ for $2 \mathrm{~min}$. The supernatants were removed to fresh tubes ready for gel electrophoresis.

\section{Western blot analyses}

Aliquots of whole-cell protein extracts or biotin-enriched protein fractions were electrophoresed on NuPAGE 4-12\%
Bis Tris gels according to the manufacturer's instructions (Life Technologies, Paisley, UK). Proteins in the gels were transferred to Hybond LFP membrane using Novel XCell II $^{\mathrm{TM}}$ blot systems according to the manufacturer's instructions (Life Technologies, Paisley, UK). Membranes were incubated with gentle agitation for $1 \mathrm{~h}$ at room temperature in Tris-buffered saline containing $1 \% \mathrm{v} / \mathrm{v}$ Tween-20 (TBST) and $2 \% \mathrm{w} / \mathrm{v}$ ECL advance blocking agent (Life Technologies, Paisley, UK). One set of blots was incubated overnight at $4{ }^{\circ} \mathrm{C}$ with gentle agitation with mouse monoclonal anti-TfR-1 at a final dilution of 1:500 and rabbit polyclonal anti- $\beta$-actin at a final dilution of $1: 10,000$ (ab57723 and ab8227, respectively, Abcam, Cambridge, UK) in TBST containing $2 \% \mathrm{w} / \mathrm{v}$ ECL advance blocking agent. Another set of blots was incubated in the same manner with rabbit polyclonal anti-FPN (MTP11-A, Alpha Diagnostics International) at a final dilution of 1:1,000 and mouse monoclonal anti- $\beta$-actin (ab8226 Abcam) at a final dilution of 1:2500. Following incubations with the primary antibodies, the blots were washed extensively with TBST. The blots were then incubated for $1 \mathrm{~h}$ at room temperature with Cy dye-labelled secondary antibodies (Life Technologies, Paisley, UK). For the blots on which TfR-1 was being detected $\mathrm{Cy} 5$ goat anti-mouse $\mathrm{IgG}$ and $\mathrm{Cy} 3$ goat anti-rabbit IgG antibodies were used, each at a final dilution of 1:2500 in TBST. For the blots detecting FPN, Cy5 goat anti-rabbit IgG and $\mathrm{Cy} 3$ goat anti-mouse $\mathrm{IgG}$ antibodies were used, each at a final dilution of 1:2500. The blots were washed extensively with TBST and then finally with TBS. After drying, the blots were scanned using a Pharos FX Plus Molecular Imager (Bio-Rad, Hemel Hempstead, UK) at $50 \mu \mathrm{m}$ using a 532-nm excitation laser and a 605-nm BP emission filter for $\mathrm{Cy} 3$ and a 695-nm excitation laser and a 635-nm BP emission filter for Cy5. Florescent signal intensities for TfR-1 and FPN were normalised first against the signal intensity for $\beta$-actin and then against the average normalised value for the control group.

\section{Statistical analysis}

Data are presented as means \pm SD. All datasets were first analysed using the D'Agostino and Pearson's omnibus normality test or the Kolmogorov-Smirnov, where groups were too small to permit use of the former. In those cases where these tests suggested the data were normally distributed, one-way ANOVA was employed to make comparisons between treatment groups with Tukey's test for post hoc comparisons when the ANOVA indicated a significant effect of treatment $(p<0.05)$. For datasets that failed the tests for normality, equivalent nonparametric tests (Kruskal-Wallis and Dunn's multiple comparisons test) were used. 
For the microarrays, data quality was evaluated, and statistical comparisons between treatments were performed, using a dedicated software pipeline (De Groot et al. 2008). The data were normalised using the GC-RMA method with "full model" option. Only genes with a normalised signal $\geq 20$ on at least 3 arrays were considered to be expressed and included in the subsequent statistical analysis. Gene expression profiles were compared between control cells and cells exposed to apical ferric NTA or basolateral Tf using unpaired $t$ tests with Bayesian correction (Limma) applying the false discovery rate (FDR) control method for multiple testing (Smyth 2004). Functional relationships between genes identified through the statistical analysis were investigated using DAVID Bioinformatic Resources 6.7 (da Huang et al. 2009a, b), using default settings and applying a FDR cut-off value of $<0.25$.

\section{Results}

Routine monitoring of TEER suggested that, under the standard culture conditions used, intact polarised cell monolayers with tight junctions were typically obtained 10-12 days following seeding of the Caco-2 cells into the inserts (data not shown). This indicated that it should be possible to obtain the desired directional supply or iron to either apical or basolateral surfaces of the cells if the supply was initiated on day 14 post-seeding. To determine whether cellular differentiation and maturation of the iron transport machinery had completed or was still ongoing from day 14 onwards, levels of mRNA for TfR-1, DMT-1 and FPN were determined by real-time RT-qPCR in the Caco- 2 cells between day 10 and 21 post-seeding. TfR-1 mRNA levels remained very consistent between day 10 and 21 postseeding (Fig. 1a). Levels of DMT-1 mRNA appeared to increase to reach a maximum at day 17 although the differences did not achieve statistical significance (Fig. 1b). Levels of FPN mRNA increased steadily over the entire timeframe (Fig. 1b) and were significantly higher at days 17 $(p<0.01), 19(p<0.05)$ and $21(p<0.001)$ compared with day 10 and at day 21 compared with both day 12 and 14 ( $p<0.05$ in both cases). Taken together, these data suggest that some establishment of the iron transport machinery was still ongoing during the third week following cell seeding although the initial stages may have started before an intact cell monolayer had fully formed.

Based on these observations, cells were treated with either free iron (as ferric NTA) added to the upper chamber (corresponding to the apical surface of the cells) or with Tfbound iron (as human holo-Tf) added to the lower chamber
Fig. 1 Expression of iron transport genes in Caco-2 cells over time following cell seeding in Transwell ${ }^{\circledR}$ permeable support plates. Values shown indicate relative mRNA levels for a TfR-1, b DMT-1 and c FPN in Caco- 2 cells determined at different days ranging from 10 to 21 postseeding cultured with normal medium. Bars and error bars indicate mean $+\mathrm{SD}(n=4$ comprised of samples generated from 1 well from each of two separate plates set up in parallel in two independent experiments). Data were compared by one-way ANOVA with Tukey's post hoc test. Asterisks indicate statistically significant differences between days $(* p<0.05, * * p<0.01$ and $* * * p<0.001$ )
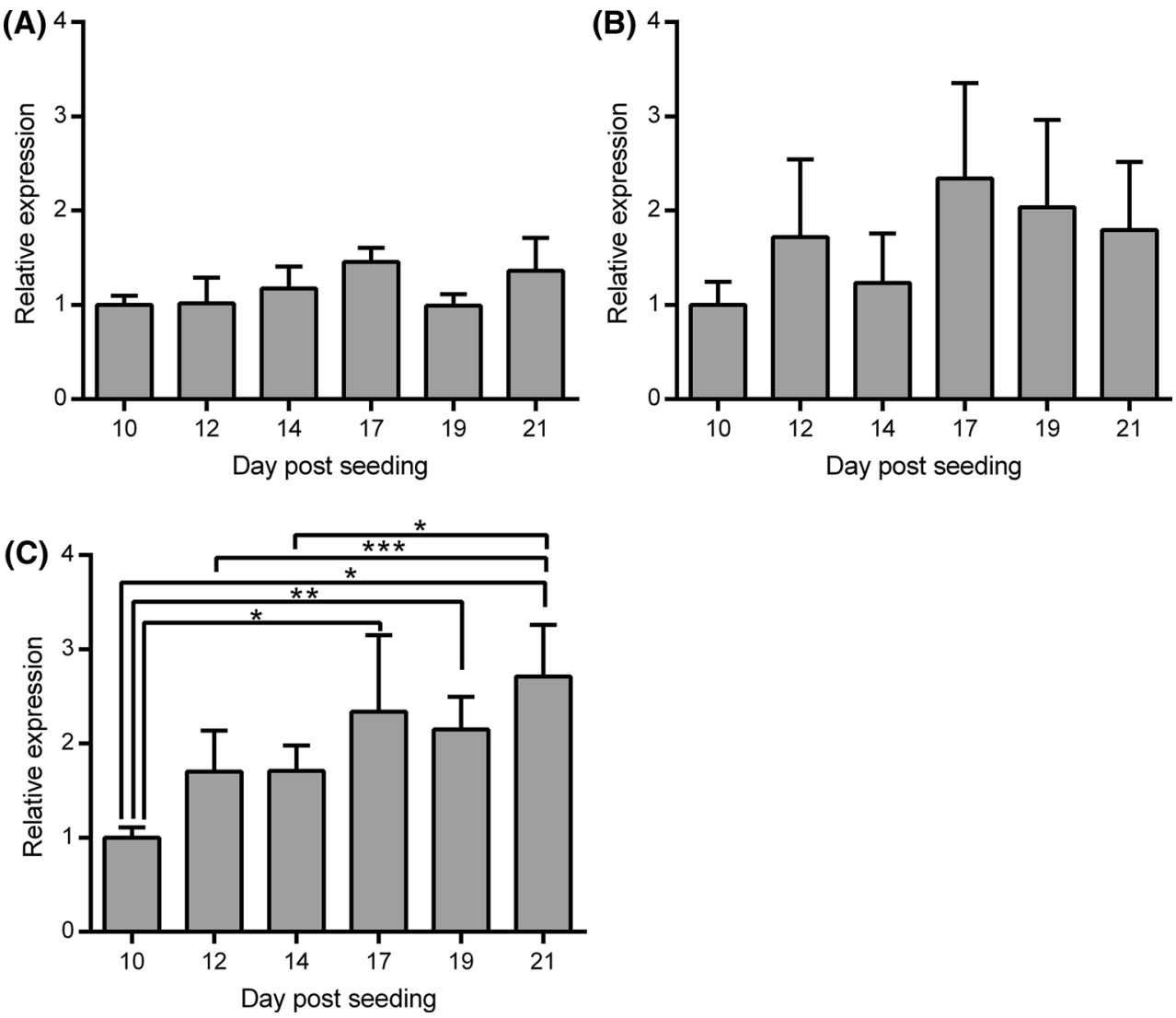

Day post seeding 
(corresponding to the basolateral surface of the cells) over the period from 14 to 21 days after cell seeding. During this time, to reduce the supply of iron to the cells from other sources, medium was used that had been prepared with metal-depleted FBS prepared by pre-treatment with Chelex resin according to the method of Alvarez-Hernandez et al. (1991). Atomic absorption analysis of the Chelextreated FBS revealed that the iron concentration was reduced to $58 \%$ of its original concentration (from 59 to $34 \mu \mathrm{M})$ as a result of this process. There were no significant differences between the different treatment groups in the TEER values of the cells layers (online resource 1).

\section{Effects of iron treatments on cellular ferritin levels}

Addition of $30 \mu \mathrm{M}$ human holo-Tf to the basolateral medium led to a substantial and significant $(p<0.05)$ increase in cellular ferritin levels (Fig. 2). Addition of ferric NTA to the apical medium at $2 \mu \mathrm{M}$ led to no significant increases in cellular ferritin levels. In marked contrast, addition of $10 \mu \mathrm{M}$ ferric NTA gave rise to very a substantial increase $(p<0.0001$ compared with controls).

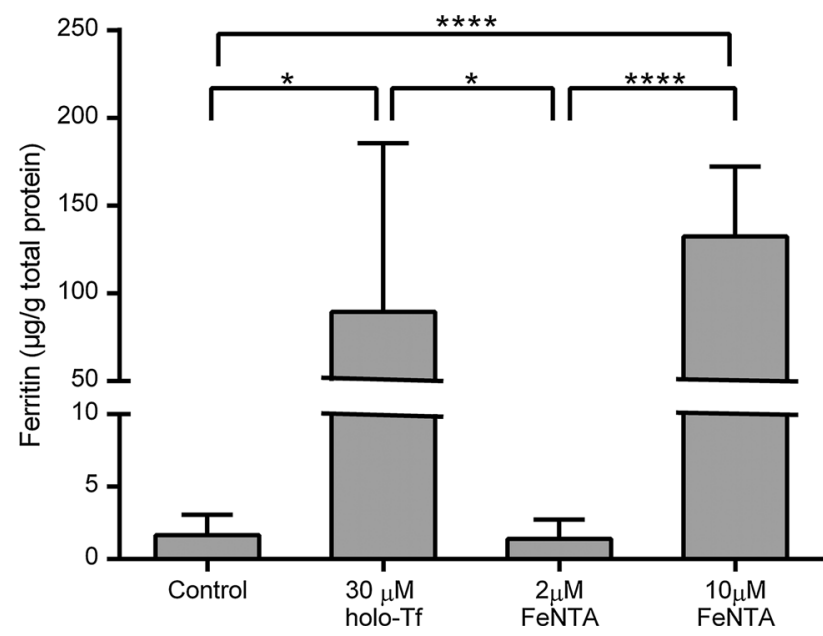

Fig. 2 Effects of different forms of iron, supplied to Caco-2 cell monolayers via either the apical or basolateral surface, on intracellular ferritin levels. Values indicate ferritin concentrations determined in extracts derived from Caco-2 cell monolayers that had been established over 2 weeks following seeding in bicameral chambers before being swapped for one further week (days 14-21 following cell seeding) into medium prepared with metal-depleted FBS only (Control), medium prepared with metal-depleted FBS plus $30 \mu \mathrm{M}$ holo-Tf added to the medium only on the basolateral side of the cells (30 $\mu \mathrm{M}$ holo-Tf) or medium prepared with metal-depleted FBS plus ferric NTA (FeNTA) at 2 or $10 \mu \mathrm{M}$ added to the medium only on the apical side of the cells. The bars and error bars indicate mean values $+\mathrm{SD}(n=8$ comprised of 4 replicate wells for each treatment from each of two separate plates set up in parallel). Data were compared by one-way ANOVA with Tukey's post hoc test. Asterisks indicate statistically significant differences between treatments $(* p<0.05$ and $* * * * p<0.0001)$
There was no significant difference between the ferritin concentrations in cell treated with $30 \mu \mathrm{M}$ basolateral holoTf and $10 \mu \mathrm{M}$ apical ferric NTA. Therefore, these concentrations were used in all subsequent experiments.

\section{Effects of iron treatments on iron transport activities}

A time course study of the rate of intracellular iron accumulation and trans-cellular iron transport across a Caco-2 cell layer 21 days after seeding, under the experimental control conditions used here, suggested that both parameters follow an approximately linear increase for at least 3-4 h (online resource 2). We chose to sample at the 2-h time point in subsequent experiments as this was typically the earliest time point at which sufficient basolateral iron had accumulated to enable accurate quantification. Analysis of iron uptake and transport following the treatment period from day 14 to 21 revealed that these two different modes of supplying iron to the cells exerted distinct effects on the cellular iron transport capacities. Apical supply of ferric NTA led to a subsequent decrease in the total amount of amount of apical iron uptake by the cells, calculated as the sum of iron retained within the cells and iron transferred from the apical to basolateral medium ( $p<0.05$ compared with control group), whereas the exposure to basolateral holo-Tf over the same time course had no effect on the total iron uptake (Fig. 3). In contrast, basolateral holo-Tf treatment significantly reduced subsequent iron transport from the apical to basolateral sides of the cell monolayer $(p<0.01$ compared both with control cells and cells exposed to apical ferric NTA), whereas exposure to apical iron over the same period had no detectable effect on this parameter (Fig. 3).

\section{Effects of iron treatments on iron transporter mRNA levels}

To investigate the molecular basis for these effects, we examined the expression of the iron transporters TfR-1, DMT1 and FPN at the level of mRNA. TfR-1, DMT-1 and FPN mRNAs were all decreased moderately but significantly by the basolateral holo-Tf treatment ( $p<0.0001$ for TfR-1 compared with control, $p<0.05$ for both DMT-1 and FPN compared with control), whereas the apical ferric NTA treatment had no significant effect on the mRNA levels for any of these genes (Fig. 4).

\section{Effects of iron treatments on whole-cell and cell surface iron transporter protein expression}

The effects of the different treatments on the whole-cell and cell surface levels of TfR- 1 and FPN, the proteins 


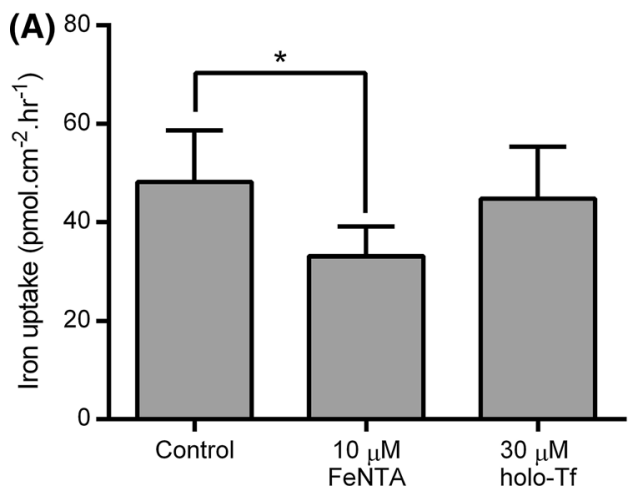

Fig. 3 Effects of treatment of Caco-2 cell monolayers with a basolateral supply of holo-Tf or an apical supply of ferric NTA on subsequent iron transport across the cell layer. Values shown indicate a total cellular iron uptake (sum of iron retained within the cells and iron transported from the apical to the basolateral medium) and b apical to basolateral iron transport of iron supplied to the apical side of the Caco-2 cell monolayer on day 21, following incubation from day 14 to 21 with medium containing metal-depleted FBS in the

responsible for moving iron across the basolateral membrane, were also investigated. Whole-cell levels of TfR-1 protein mirrored the patterns observed for TfR-1 mRNA expression. Basolateral supply of holo-Tf led to a moderate but nonetheless significant decrease in whole-cell TfR-1 protein levels compared to controls $(p<0.05)$, while the levels in cells treated with apical ferric NTA were intermediary between controls and those treated with basolateral holo-Tf but were not significantly different to either (Fig. 5a). Intriguingly, the analysis of TfR-1 protein levels at the cell surface, as assessed by enrichment of the biotinylated protein fraction following treatment of intact cells with a protein biotinylating reagent, revealed a rather different pattern. There were no significant differences between cell surface levels of TfR-1 in cells treated with basolateral holo-Tf and controls. However, treatment of the cells with apical ferric NTA led to a small but significant reduction in the amount of TfR- 1 at the cell surface $(p<0.01$ compared with both the control and basolateral holo-Tf groups) (Fig. 5b).

The pattern of FPN protein levels in whole-cell extracts was also similar to the pattern of FPN mRNA levels although for the protein analysis, no significant differences were observed between any of the groups (Fig. 5c). When cell surface levels of FPN protein were analysed, levels were found to be significantly lower in the cells treated with basolateral holo-Tf compared with those treated with apical ferric NTA $(p<0.05)$ (Fig. 5d).

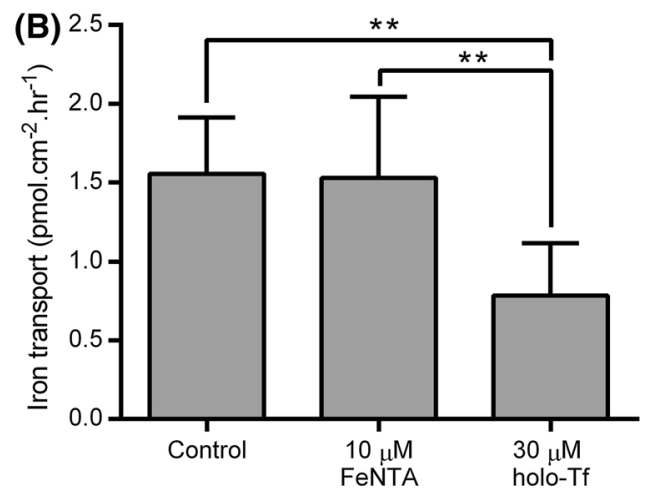

absence of any added iron (Control), presence of $10 \mu \mathrm{M}$ ferric NTA added to the apical side of the cells only $(10 \mu \mathrm{M}$ FeNTA) or of $30 \mu \mathrm{M}$ holo-Tf added to the basolateral side of the cells only ( $30 \mu \mathrm{M}$ holoTf). Bars and error bars indicate mean $+\mathrm{SD}(n=8$ comprised of 4 replicate wells for each treatment from each of two separate plates set up in parallel). Data were compared by one-way ANOVA with Tukey's post hoc test. Asterisks indicate statistically significant differences between treatments $(* p<0.05$ and $* * p<0.01)$

\section{Effects of iron on gene transcript profiles}

The wider impact of supplementation with apical iron or basolateral holo-Tf on Caco-2 gene transcript profiles in Caco- 2 cells was examined by microarray analysis of RNA samples extracted on day 21 at the end of the iron supplementation period (five samples for each treatment group were analysed each on separate arrays). When a conservative FDR cut-off of $<0.05$ was applied for the statistical comparison of the genes transcript profiles, seven genes were identified as differentially expressed in cells treated with basolateral holo-Tf compared with controls (Table 2), and there were no differences detectable between the cells treated with apical ferric NTA and controls. This suggests that neither iron treatment elicited widespread and substantial changes in overall patterns of gene expression at the level of RNA. A less conservative statistical analysis, performed without applying the FDR control (i.e. uncorrected $p<0.05$ ), was used to generate gene lists for functional annotation enrichment analysis with the DAVID Bioinformatics resource 6.7. This approach produced lists of 605 and 443 genes for cells treated with basolateral holo-Tf and apical ferric NTA, respectively, compared with controls. A relatively small number of biological pathways or processes were identified as significantly enriched in these gene lists (FDR $<0.25$ ) (online resource 3 ). The analysis highlighted enrichment of genes involved in a number of lipid metabolic processes in response to basolateral holo-Tf treatment, whereas the apical ferric NTA appeared to affect expression of a number of categories of nuclear proteins. 

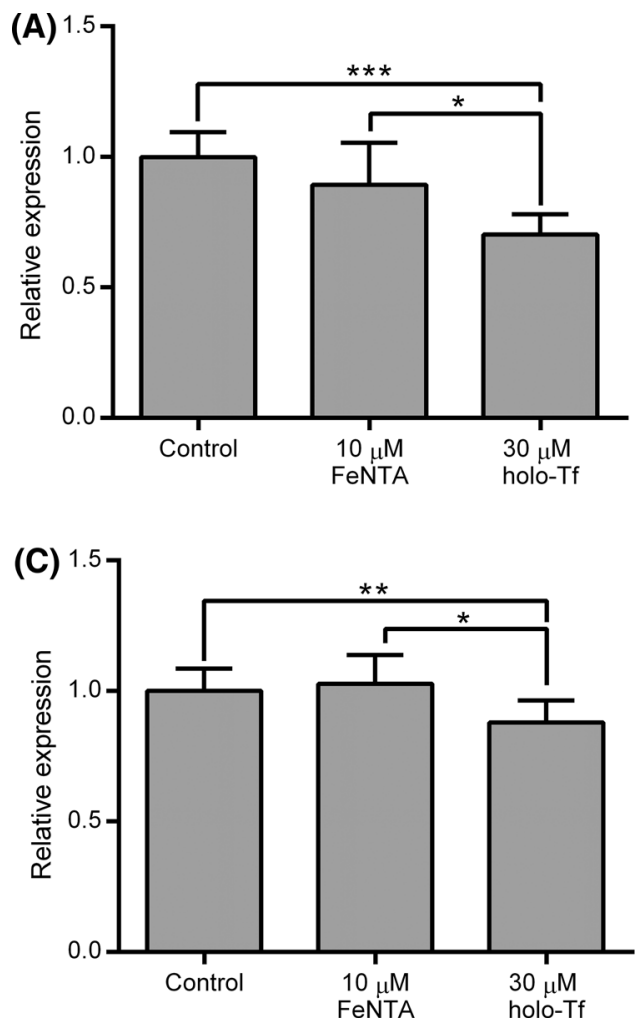

Fig. 4 Effects of treatment of Caco-2 cell monolayers with a basolateral supply of holo-Tf or an apical supply of ferric NTA on mRNA levels for iron transport genes. Values shown indicate relative mRNA levels for a TfR-1, b DMT-1 and c FPN in Caco-2 cells determined at day 21 post-seeding following incubation from day 14 to 21 of confluent Caco-2 cell monolayers established in bicameral chamber with medium containing metal-depleted FBS in the absence of any added iron (Control), presence of $10 \mu \mathrm{M}$ ferric NTA added to the apical side of the cells only (10 $\mu \mathrm{M}$ FeNTA) or of $30 \mu \mathrm{M}$ holo-Tf added to the basolateral side of the cells only ( $30 \mu \mathrm{M}$ holo-Tf). Bars

DMT-1 and TfR-1 were among the genes identified using the less stringent statistical analysis. The data for these genes generally corresponded with the results obtained independently by real-time RT-qPCR. DMT-1 mRNA levels were significantly reduced in holo-Tf treatment cells compared with controls $(p<0.05)$ and TfR-1 levels were lower in holo-Tf-treated cells compared with both controls and cells treated with apical ferric NTA $(p<0.05)$. Inspection of the microarray data for expression FPN revealed that mean levels of FPN mRNA were lowest in the holo-Tf-treated cells, although there were no statistically significant differences. There were also no significant differences in mRNA levels between any of the treatment groups for other genes involved in iron transport such as cytochrome $\mathrm{b}$ reductase 1 or hephaestin or in the mRNA levels of ferritin light and heavy chain. Equally, mRNA levels of common markers of cell differentiation, such as lactase, sucrose isomaltase, dipeptidyl peptidase IV and intestinal alkaline phosphatase (Ferruzza et al. 2012b;

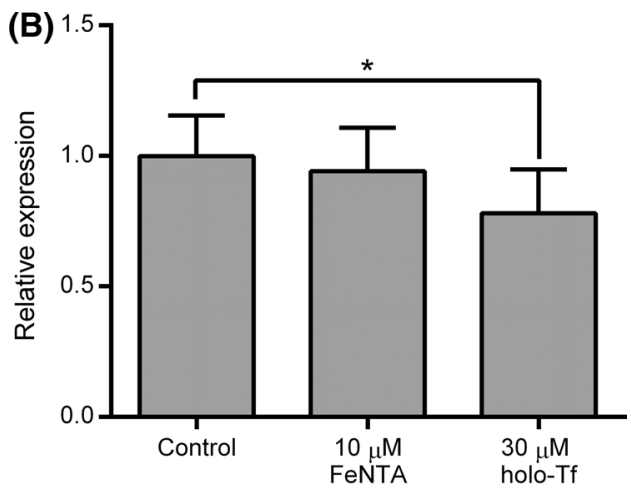

and error bars indicate mean $+\mathrm{SD}(n=10$ comprised of samples generated from 1 or 2 wells for each treatment from each of three separate plates set up in parallel with a total of five samples from each of two independent experiments). Data were compared either by Kruskal-Wallis test with Dunn's multiple comparison post hoc test (for DMT-1 and TfR-1 where at least one data set did not pass the D'Agostino and Pearson's omnibus normality test) or by one-way ANOVA with Tukey's post hoc test (for FPN). Asterisks indicate statistically significant differences between treatments $\left({ }^{*} p<0.05\right.$, $* * p<0.01$ and $* * * p<0.001)$

Jumarie and Malo 1991; Sambuy et al. 2005), did not differ between the treatment groups, suggesting that the iron treatments had not led to differences in iron transport as a result of changing the rate or extent of the differentiation process.

\section{Discussion}

The differentiation of enterocytes along crypt-villus axis involves, among many other changes, the coordinated activation of cellular machinery for iron absorption (CanonneHergaux et al. 1999; Donovan et al. 2000; Vulpe et al. 1999). It has been postulated that systemic iron status during the differentiation process ultimately programmes the iron uptake and transport capacity of mature villus enterocytes (Charlton et al. 1965; Conrad et al. 1964; Waheed et al. 2002). However, since the identification of hepcidin as the primary iron stores regulator, this concept has been 
(A)
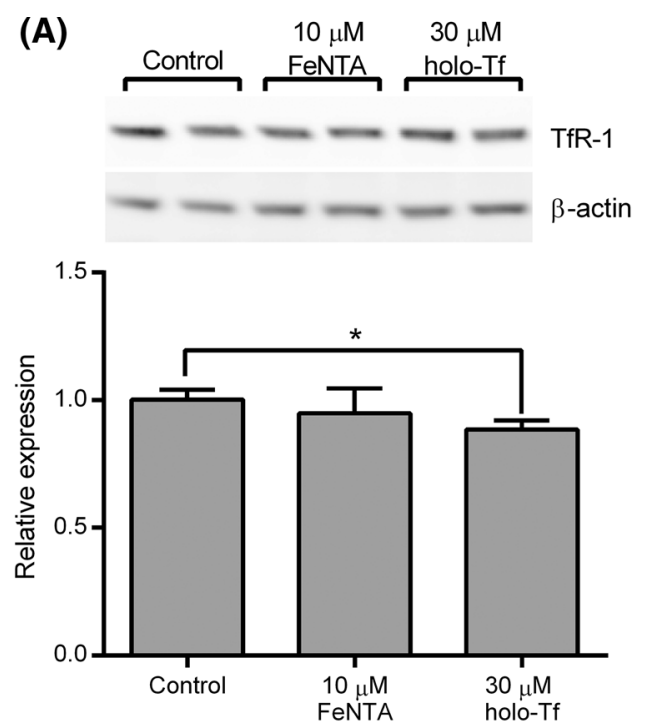

(C)
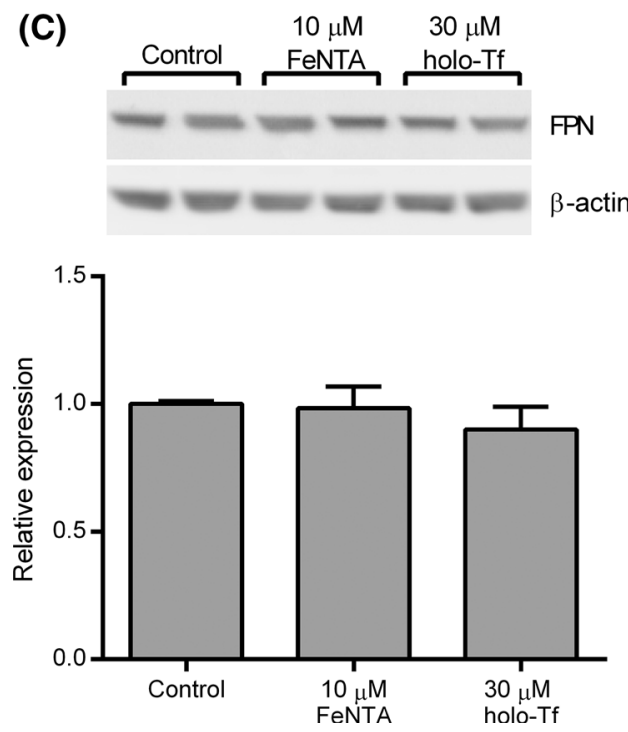

Fig. 5 Effects of treatment of Caco-2 cell monolayers with a basolateral supply of holo-Tf or an apical supply of ferric NTA on whole-cell and cell surface levels of proteins responsible for transport of iron across the basolateral membrane of enterocytes. Relative protein levels for whole-cell TfR-1 (a), cell surface TfR-1 (b), wholecell FPN (c) and cell surface FPN (d) in Caco-2 cells determined at day 21 post-seeding following incubation from day 14 to 21 of confluent Caco- 2 cell monolayers established in bicameral chamber with medium containing metal-depleted FBS in the absence of any added iron (Control), the presence of $10 \mu \mathrm{M}$ ferric NTA added to the

challenged and the current prevailing opinion is that the iron transport capacity of villus enterocytes may be acutely regulated by circulating hepcidin levels rather than preprogrammed during differentiation (Frazer et al. 2004). Nonetheless, numerous studies have demonstrated that the iron status of enterocytes can affect their iron transport capacity, suggesting that this could be an additional modulatory mechanism (Gangloff et al. 1996; Nunez et al. 1996; Sharp et al. 2002; Tallkvist et al. 2000, 2003).
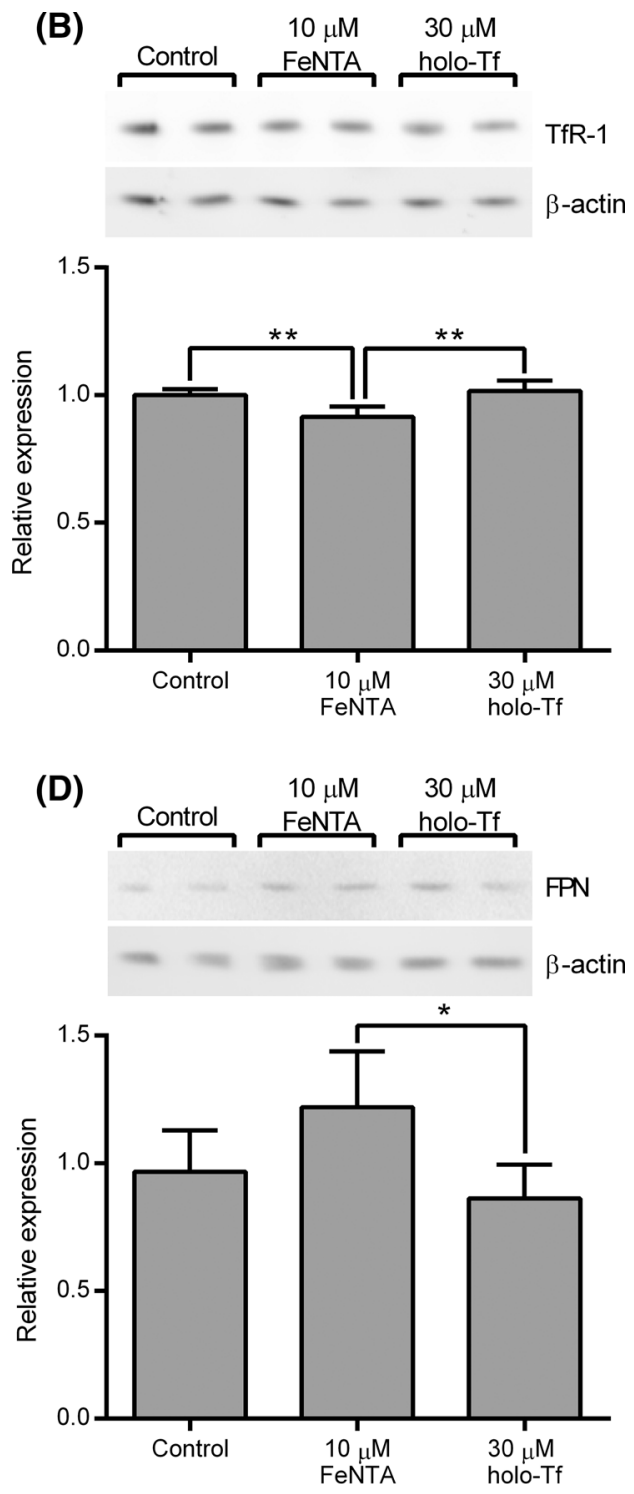

apical side of the cells only ( $10 \mu \mathrm{M}$ FeNTA) or $30 \mu \mathrm{M}$ holo-Tf added to the basolateral side of the cells only ( $30 \mu \mathrm{M}$ holo-Tf). Insets above each graph depict and an example of the one of the western blots from which the data for the graph were generated. Bars and error bars in the graphs indicate mean $+\mathrm{SD}(n=6$ comprised of samples generated from 2 wells for each treatment from each of 3 separate plates set up in parallel). Data were compared by one-way ANOVA with Tukey's post hoc test. Asterisks indicate statistically significant differences between treatments $(* p<0.05$ and $* * p<0.01)$

We employed the Caco-2 cell model of the gut epithelium to compare the effects of iron loading from different sources during differentiation on subsequent iron transport activities and transporter gene expression. After growing to confluence on permeable membrane supports, Caco- 2 cell monolayers undergo morphological and functional differentiation that corresponds with many aspects of normal enterocyte differentiation, including activation of genes involved in the transport of iron across the cell layer (Pinto 
Table 2 Genes differentially expressed in response to addition of holo-Tf to the basolateral medium of confluent Caco- 2 cell monolayers from day 14 to day 21 after cell seeding

\begin{tabular}{lllrr}
\hline Affymetrix Probeset ID & Gene & Gene symbol & Fold change $^{\mathrm{a}}$ & Uncorrected $p$ value $^{\mathrm{b}}$ \\
\hline 226837_at & Sprouty-related, EVH1 domain containing 1 & SPRED1 & 2.19 & $9.77 \mathrm{E}-06$ \\
208891_at & Dual-specificity phosphatase 6 & DUSP6 & 1.51 & $1.01 \mathrm{E}-05$ \\
232321_at & Mucin 17 & MUC17 & 3.61 & $6.50 \mathrm{E}-06$ \\
227246_at & Pleiotropic regulator 1 & PLRG1 & -1.79 & $1.05 \mathrm{E}-05$ \\
209101_at & Connective tissue growth factor & CTGF & 1.64 & $6.89 \mathrm{E}-06$ \\
208383_s_at & Phosphoenolpyruvate carboxykinase 1 & PCK1 & 2.00 & $4.32 \mathrm{E}-06$ \\
211357_s_at & Aldolase B & ALDOB & 1.48 & $2.10 \mathrm{E}-05$ \\
\hline
\end{tabular}

${ }^{a}$ Positive values indicate increased expression following holo-Tf treatment (mean expression in holo-Tf-treated cells/mean expression in controls). Negative values indicate decreased expression following holo-Tf treatment (-mean expression in control cells/mean expression in holo-Tf treated cells)

b Derived from unpaired $t$ tests with Bayesian correction (Limma) comparing data from microarrays for holo-Tf treated and control cells $(n=5$ for both treatments)

${ }^{c}$ False discovery rate

et al. 1983; Sharp et al. 2002; Tremblay et al. 2006). The time taken following seeding for Caco-2 cells to reach confluence and differentiate depends on a number of factors including the source and passage number of the cells, the cell seeding density, the culture conditions and the marker or markers of differentiation used (Ferruzza et al. 2012a; Pinto et al. 1983; Sambuy et al. 2005; Zucco et al. 2005). Analysis of the pattern of iron transporter gene expression over time following cell seeding in our cell culture system indicated that while some of the initial upregulation of DMT-1 and FPN mRNA levels may occur prior to the formation of an intact monolayer, the process appeared to continue beyond the formation of the intact monolayer, thus making it possible to supply iron to the cells during the latter stages of differentiation in a direction-specific manner.

Ferric NTA was supplied only to the apical side of the cells to represent dietary iron or holo-Tf was supplied only to the basolateral side to represent systemic iron. The effects of these different forms of iron supply on cellular iron status were evaluated by analysis of cellular ferritin levels. The cellular ferritin content of Caco-2 cells is known to be sensitive to iron supply and has been used widely as an indirect marker of the cellular iron content of Caco- 2 cell systems (Arredondo et al. 1997; Gangloff et al. 1996; Glahn et al. 1998; Martini et al. 2002). In line with previous reports, substantial increases in cellular ferritin content were observed following both forms of iron exposure, indicating that the cells were proficient at taking up both free iron at their apical surface and Tf-bound iron at their basolateral surface (Nunez et al. 1996). The levels of cellular ferritin were similar at the end of both treatments, suggesting that the cells had achieved similar levels of iron loading. Since iron-saturated holo-Tf has two atoms of iron bound per protein molecule, the total iron concentration used for the basolateral supply of holo-Tf ( $30 \mu \mathrm{M}$ holo-Tf, equivalent to $60 \mu \mathrm{M}$ iron) was sixfold higher than the iron concentration used for the apical treatment of cells with ferric NTA $(10 \mu \mathrm{M})$. This might appear to suggest that, on a molar basis, the ferric NTA was taken up by the cells more efficiently than the iron from the holo-Tf, contrary to previous observations (Nunez et al. 1996). However, preliminary experiments in which other concentrations of iron were tested had indicated that treatment with lower holo-Tf concentrations $(10 \mu \mathrm{M})$ over the same seven day period led to only marginally, and not significantly, lower cellular ferritin than the $30 \mu \mathrm{M}$ treatment (data not shown), suggesting a nonlinear dose response with both 10 and $30 \mu \mathrm{M}$ basolateral holo-Tf achieving levels of cellular ferritin similar to that obtained with the apical ferric NTA.

Ionic iron transported across the apical membrane via DMT-1 and Tf-bound iron taken up by endocytosis of TfR1 at the basolateral membrane feed iron into the labile iron pool, which regulates ferritin levels via the activity of IRPIRE system, in different ways with different dynamics. While it is plausible that, after seven days of the two iron treatments, the Caco- 2 cells had achieved a new steady state of iron status for which ferritin protein levels are a good indicator, we cannot rule out the possibility that the different pathways of iron uptake lead to differences in iron partitioning between intracellular pools that could play a role in the differences observed in iron transport.

Having identified suitable conditions to iron load the cells, the effects on iron transport were investigated. The basolateral supply of holo-Tf during the cellular differentiation phase led to a reduction of approximately $50 \%$ in subsequent net iron transport from the apical to basolateral side of the cells. This occurred in the absence of any 
apparent change in iron uptake by the cells from apical the medium. These data suggest that the effect of the basolateral supply of holo-Tf was specifically to decrease iron export across the basolateral membrane. In contrast, ferric iron supplied to the apical surface of the cells during differentiation led to a moderate (approximately $33 \%$ ) reduction in net total iron uptake without altering the amount of iron transported across the cell layer from the apical to the basolateral compartment. This latter observation is similar to the effect observed in at least one previous study where Caco-2 cells were loaded with iron (Gangloff et al. 1996). However, other groups have reported that loading of Caco-2 cells with iron leads to decreases in both iron uptake at the apical membrane and export across the basolateral membrane (Nunez et al. 1996; Tallkvist et al. 2000, 2003). The variations between these studies may result from the use of different forms and concentrations of iron, differences in media composition and variation in the treatment duration and the state of differentiation of the cells when the iron loading commenced. One of the most critical considerations, in this regard, is that the ferric NTA in the experiments described here was supplied only to the apical surface of the cells, whereas in most previous studies, the medium on both sides of the cells was supplemented with iron. Nunez and co-workers have demonstrated that Caco-2 cells are capable of taking up ferrous iron at both the apical and basolateral surfaces, and they and others have demonstrated that iron intake leads to a redistribution of iron transporters (Johnson et al. 2005; Nunez et al. 2010; Sharp et al. 2002). It is, therefore, plausible that supply of iron to only one surface of the cells may elicit a pattern of transporter redistribution that differs from that obtained when iron is added to both sides.

We sought to gain further insight into the basis for these different effects on iron transport first by analysing the expression of the iron transporter genes both at the level of the mRNA and the protein. The supply of basolateral holo$\mathrm{Tf}$ to the cells during differentiation was associated with moderate reductions in the mRNA levels of TfR-1, DMT-1 and FPN, whereas the supply of iron to the apical surface had no significant effect on any of these genes. The latter was a somewhat unexpected result since there is considerable evidence that all three of these genes can be regulated by cellular iron status (Gunshin et al. 2001; Martini et al. 2002; Sharp et al. 2002; Tallkvist et al. 2000, 2001, 2003; Zoller et al. 2002). Ferritin and TfR-1 are the classic examples of genes regulated in opposing directions via the IRP-IRE system. Expression of DMT-1 and FPN may also be regulated, in part, by this system. At least four mRNA splice variants, which differ in their first and last exons, are synthesised from the DMT-1 gene in duodenum and in Caco-2 cells. In two of these, the last exon includes an IRE, which contributes to, but does not appear to be the only mechanism for, the iron-responsive regulation of DMT-1 gene transcript levels (Hubert and Hentze 2002; Zoller et al. 2002). In the experiments described here, the primers and probe used for the real-time RT-qPCR analysis of DMT-1 were designed to amplify all the splice variants so as to obtain an overview of total mRNA levels for this gene. However, this does mean that it would not have been possible to detect changes specific to individual variants.

The mRNA for FPN also contains an IRE in its $5^{\prime}$ untranslated region, akin to the structure found in the ferritin mRNAs and shown to bind IRP in vitro. However, the functionality of this element appears to be splice variant and tissue specific (Eisenstein and Ross 2003). For example, duodenal epithelial cells and erythroid precursor cells have been shown to expresses a variant form of the FPN mRNA lacking the IRE, thus enabling them to avoid suppression of FPN expression under iron deficient conditions (Zhang et al. 2009). In fact, enterocyte FPN expression has been found to increase under conditions of iron depletion and decrease with iron loading (Martini et al. 2002; Zoller et al. 2002), suggesting that other, most likely transcriptional (Zoller et al. 2002), mechanisms are predominantly responsible for regulation of the expression of this gene.

While the patterns of total cellular TfR-1 and FPN protein levels following the different treatments matched the pattern of the corresponding mRNAs, a rather different picture was obtained when the levels of these transporters at the cell surface were analysed. Apical ferric NTA treatment appeared to reduce the number of TfR-1 molecules at the cell surface, while the basolateral holo-Tf had no detectable effect. Apical ferric NTA moderately increased the level of FPN at the cell surface, while basolateral holo-Tf reduced FPN cell surface levels moderately such that, while neither group differed significantly from the control group, the levels in cells exposed to apical ferric NTA were significantly lower than those in cells treated with basolateral holo-Tf. Unfortunately, we failed to obtain western blot data of sufficient quality to quantify whole-cell and cell surface DMT-1 protein levels. However, Nunez and co-workers have demonstrated previously that supply of iron to the apical surface of Caco-2 cells leads to rapid internalisation of DMT-1 away from the brush-border membrane and that iron feeding of rats leads to redistribution of DMT-1 from the apical into basal cytoplasmic domains of enterocytes in the duodenum (Nunez et al. 2010). Taken together, these observations support the hypothesis that the supply of iron to the apical surface of Caco- 2 cells caused the down-regulation of iron uptake as a result of redistribution of DMT-1 away from the apical surface of the cells, while supply of holo-Tf to the basolateral surface of the cells decreased iron transport via a combination of suppressed FPN expression and its redistribution away from the basolateral surface of the cells. 
However, one limitation of the method used in the current study to quantify cell surface expression is that the apical and basolateral surfaces of the cells were treated with the biotinylating reagent simultaneously. As a result, it is not possible to determine from these data the relative levels of the iron transporters at the apical and basolateral surfaces. In differentiated Caco- 2 cells grown on permeable membrane supports, TfR-1 appears to be found almost exclusively in the basolateral region (Nunez et al. 2010). On the other hand, as noted above, there is evidence that DMT-1, and also FPN, may be found at both the apical and basolateral cell surfaces in differentiated Caco- 2 cell monolayers grown on permeable membrane supports and that iron supply can cause redistribution of both transporters across these surfaces (Nunez et al. 2010). FPN located within the apical membrane could affect the apparent rate of iron uptake by exporting some back into the apical medium. DMT-1 within the basolateral membrane provides a potential mechanism for reabsorption of iron from the basolateral medium. Redistribution of these transporters between the apical and basolateral membranes could contribute to the changes in iron transport observed following exposure of the cells to basolateral holo-Tf or apical ferric NTA by altering the rate of iron uptake at the apical surface and export at the basolateral surface. It could also alter the rate of export of iron from the cell back into the apical medium and reabsorption of iron from the basolateral medium back into the cells. Given that the changes in mRNA for DMT-1 and FPN and total protein levels for FPN were small, it is likely that redistribution of one or both of these transporters contributes to the changes in iron transport observed.

We used microarray analysis to investigate the wider impact of the two iron treatments on the Caco- 2 cells. The results indicated that both apical ferric NTA and basolateral supply of holo-Tf elicited relatively minor changes in gene expression patterns. Applying stringent statistical criteria (FDR $<0.05$ ), no genes were identified as being differentially regulated in response to apical ferric NTA, while just seven genes were identified as being differentially expressed in response to basolateral holo-Tf supply. Of these seven, four play roles in key cellular functions such as growth, differentiation and cell death. Sprouty-related EVH1 domain containing 1 (SPRED1) and dualspecificity phosphatase 6 (DUSP6) are negative regulators of MAP kinase signalling (Gonzalez-Sarrias et al. 2009; Quintanar-Audelo et al. 2011). Pleiotropic regulator 1 (PLRG1) is a component of the spliceosome that appears to be involved in regulation of proliferation and apoptosis (Kleinridders et al. 2009) and connective tissue growth factor (CTGF) regulates processes such as mitosis, adhesion, apoptosis and migration in many cells (Brigstock 2003). However, the functional annotation enrichment analysis of the wider gene lists did not identify significant enrichment for groups of genes involved any of these processes and inspection of the array data for established markers of Caco- 2 cell differentiation revealed no differences between any of the treatments.

Two of the other genes in the list of seven identified as being differentially regulated by holo-Tf treatment (phosphoenolpyruvate carboxykinase 1 (PCK1) and aldolase $\mathrm{B}$ (ALDOB)) are involved in glucose metabolism (Ito et al. 1998), while the final one was a mucin (MUC17). The observation of increased expression of a mucin following holo-Tf treatment is intriguing since it has been proposed that mucins may play an important role in enhancing absorption of dietary iron by helping to maintain ionic iron in a soluble form (Conrad et al. 1991). Caco-2 cells have been shown to express some mucin genes including MUC17 (Resta-Lenert et al. 2011), but Caco-2 cell monolayers do not develop a mucous layer so the significance of this observation is not clear.

Perhaps surprisingly, the functional annotation enrichment analysis did not highlight any processes associated with iron or metal homeostasis. Analysis of the microarray data for individual key genes involved in iron homeostasis suggested that the iron loading only led to small changes in mRNA levels. Nonetheless, clear changes in iron transport across the cell layer were evident, suggesting that posttranscriptional regulatory processes are likely to be involved. Thus, in conclusion, while it is well known that the iron status of cells can affect their iron transport capacity, this is the first direct evidence we are aware of that the form and direction of iron supply to enterocytes may also have distinct functional consequences.

Acknowledgments The authors would like to thank David Hart for his assistance with the atomic absorption spectrophotometric analyses. This work was supported by the Biotechnology and Biological Sciences Research Council (Institute core strategic grant). The microarray component of the study was supported, in part, by NuGO (The European Nutrigenomics Organization: linking genomics, nutrition and health research; CT-2004-505944), a Network of Excellence funded by the European Commission's Research Directorate General under Priority Thematic Area 5 Food Quality and Safety Priority of the Sixth Framework Programme for Research and Technological Development.

\section{Conflict of interest None.}

Ethical standard This article does not contain any studies with human or animal subjects performed by the any of the authors.

\section{References}

Alvarez-Hernandez X, Nichols GM, Glass J (1991) Caco-2 cell line: a system for studying intestinal iron transport across epithelial cell monolayers. Biochim Biophys Acta 1070:205-208 
Arredondo M, Orellana A, Garate MA, Nunez MT (1997) Intracellular iron regulates iron absorption and IRP activity in intestinal epithelial (Caco-2) cells. Am J Physiol 273:G275-G280

Bedrine-Ferran $\mathrm{H}$ et al (2004) Transcriptome variations in human CaCo-2 cells: a model for enterocyte differentiation and its link to iron absorption. Genomics 83:772-789. doi:10.1016/j.ygeno. 2003.11.014

Brasse-Lagnel C, Karim Z, Letteron P, Bekri S, Bado A, Beaumont C (2011) Intestinal DMT1 cotransporter is down-regulated by hepcidin via proteasome internalization and degradation. Gastroenterology 140(1261-1271):e1261. doi:10.1053/j.gastro.2010. 12.037

Brigstock DR (2003) The CCN family: a new stimulus package. J Endocrinol 178:169-175

Canonne-Hergaux F, Gruenheid S, Ponka P, Gros P (1999) Cellular and subcellular localization of the Nramp2 iron transporter in the intestinal brush border and regulation by dietary iron. Blood 93:4406-4417

Charlton RW, Jacobs P, Torrance JD, Bothwell TH (1965) The role of the intestinal mucosa in iron absorption. $J$ Clin Invest 44:543-554. doi:10.1172/JCI105167

Collins JF, Franck CA, Kowdley KV, Ghishan FK (2005) Identification of differentially expressed genes in response to dietary iron-deprivation in rat duodenum. Am J Physiol Gastrointest Liver Physiol 288:G964-G971. doi:10.1152/ajpgi.00489.2004

Conrad ME, Weintraub LR, Crosby WH (1964) The role of the intestine in iron kinetics. J Clin Invest 43:963-974. doi:10.1172/ JCI104982

Conrad ME, Umbreit JN, Moore EG (1991) A role for mucin in the absorption of inorganic iron and other metal cations. A study in rats. Gastroenterology 100:129-136

da Huang W, Sherman BT, Lempicki RA (2009a) Bioinformatics enrichment tools: paths toward the comprehensive functional analysis of large gene lists. Nucleic Acids Res 37:1-13. doi:10. 1093/nar/gkn923

da Huang W, Sherman BT, Lempicki RA (2009b) Systematic and integrative analysis of large gene lists using DAVID bioinformatics resources. Nat Protoc 4:44-57. doi:10.1038/nprot.2008. 211

De Groot PJ, Reiff C, Mayer C, Muller M (2008) NuGO contributions to GenePattern. Genes Nutr 3:143-146. doi:10.1007/s12263008-0093-2

Donovan A et al (2000) Positional cloning of zebrafish ferroportin1 identifies a conserved vertebrate iron exporter. Nature 403:776-781. doi:10.1038/35001596

Eisenstein RS, Ross KL (2003) Novel roles for iron regulatory proteins in the adaptive response to iron deficiency. J Nutr 133:1510S-1516S

Fernandez FJ, Kahn HL (1971) Clinical methods for atomic absorption spectroscopy. Clin Chem Newsl 3:24

Ferruzza S, Rossi C, Scarino ML, Sambuy Y (2012a) A protocol for differentiation of human intestinal Caco-2 cells in asymmetric serum-containing medium. Toxicol In Vitro 26:1252-1255. doi:10.1016/j.tiv.2012.01.008

Ferruzza S, Rossi C, Scarino ML, Sambuy Y (2012b) A protocol for in situ enzyme assays to assess the differentiation of human intestinal Caco-2 cells. Toxicol In Vitro 26:1247-1251. doi:10. 1016/j.tiv.2011.11.007

Fleet JC, Wang L, Vitek O, Craig BA, Edenberg HJ (2003) Gene expression profiling of Caco-2 $\mathrm{BBe}$ cells suggests a role for specific signaling pathways during intestinal differentiation. Physiol Genomics 13:57-68. doi:10.1152/physiolgenomics. 00152.2002

Frazer DM, Anderson GJ (2005) Iron imports. I. Intestinal iron absorption and its regulation. Am J Physiol Gastrointest Liver Physiol 289:G631-G635
Frazer DM, Wilkins SJ, Becker EM, Murphy TL, Vulpe CD, McKie AT, Anderson GJ (2003) A rapid decrease in the expression of DMT1 and Dcytb but not Ireg1 or hephaestin explains the mucosal block phenomenon of iron absorption. Gut 52:340-346

Frazer DM, Inglis HR, Wilkins SJ, Millard KN, Steele TM, McLaren GD, McKie AT, Vulpe CD, Anderson GJ (2004) Delayed hepcidin response explains the lag period in iron absorption following a stimulus to increase erythropoiesis. Gut 53:1509-1515

Gangloff MB, Lai C, Van Campen DR, Miller DD, Norvell WA, Glahn RP (1996) Ferrous iron uptake but not transfer is downregulated in Caco-2 cells grown in high iron serum-free medium. J Nutr 126:3118-3127

Ganz T, Nemeth E (2006) Iron imports. IV. Hepcidin and regulation of body iron metabolism. Am J Physiol Gastrointest Liver Physiol 290:G199-G203

Glahn RP, Gangloff MB, Van Campen DR, Miller DD, Wien EM, Norvell WA (1995) Bathophenanthrolene disulfonic acid and sodium dithionite effectively remove surface-bound iron from Caco-2 cell monolayers. J Nutr 125:1833-1840

Glahn RP, Lee OA, Yeung A, Goldman MI, Miller DD (1998) Caco-2 cell ferritin formation predicts nonradiolabeled food iron availability in an in vitro digestion/Caco-2 cell culture model. J Nutr 128:1555-1561

Gonzalez-Sarrias A, Espin JC, Tomas-Barberan FA, Garcia-Conesa MT (2009) Gene expression, cell cycle arrest and MAPK signalling regulation in Caco-2 cells exposed to ellagic acid and its metabolites, urolithins. Mol Nutr Food Res 53:686-698. doi: 10.1002/mnfr.200800150

Gunshin H, Mackenzie B, Berger UV, Gunshin Y, Romero MF, Boron WF, Nussberger S, Gollan JL, Hediger MA (1997) Cloning and characterization of a mammalian proton-coupled metal-ion transporter. Nature 388:482-488

Gunshin $\mathrm{H}$ et al (2001) Iron-dependent regulation of the divalent metal ion transporter. FEBS Lett 509:309-316

Han O, Fleet JC, Wood RJ (1999) Reciprocal regulation of HFE and NNamp2 gene expression by iron in human intestinal cells. J Nutr 129:98-104

Hubert N, Hentze MW (2002) Previously uncharacterized isoforms of divalent metal transporter (DMT)-1: implications for regulation and cellular function. Proc Natl Acad Sci USA 99:12345-12350. doi:10.1073/pnas.192423399

Hurst R, Elliott RM, Goldson AJ, Fairweather-Tait SJ (2008) Semethylselenocysteine alters collagen gene and protein expression in human prostate cells. Cancer Lett 269:117-126. doi:10.1016/j. canlet.2008.04.025

Ito J, Kuzumaki T, Otsu K, Iuchi Y, Ishikawa K (1998) Hormonal regulation of aldolase $\mathrm{B}$ gene expression in rat primary cultured hepatocytes. Arch Biochem Biophys 350:291-297

Johnson DM, Yamaji S, Tennant J, Srai SK, Sharp PA (2005) Regulation of divalent metal transporter expression in human intestinal epithelial cells following exposure to non-haem iron. FEBS Lett 579:1923-1929. doi:10.1016/j.febslet.2005.02.035

Jumarie C, Malo C (1991) Caco-2 cells cultured in serum-free medium as a model for the study of enterocytic differentiation in vitro. J Cell Physiol 149:24-33. doi:10.1002/jcp.1041490105

King IS, Sepulveda FV, Smith MW (1981) Cellular distribution of neutral and basic amino acid transport systems in rabbit ileal mucosa. J Physiol 319:355-368

Kleinridders A, Pogoda HM, Irlenbusch S, Smyth N, Koncz C, Hammerschmidt M, Bruning JC (2009) PLRG1 is an essential regulator of cell proliferation and apoptosis during vertebrate development and tissue homeostasis. Mol Cell Biol 29:3173-3185. doi:10.1128/MCB.01807-08

Kruszewski M (2003) Labile iron pool: the main determinant of cellular response to oxidative stress. Mutat Res 531:81-92 
Lymboussaki A, Pignatti E, Montosi G, Garuti C, Haile DJ, Pietrangelo A (2003) The role of the iron responsive element in the control of ferroportin1/IREG1/MTP1 gene expression. J Hepatol 39:710-715

Martini LA, Tchack L, Wood RJ (2002) Iron treatment downregulates DMT1 and IREG1 mRNA expression in Caco-2 cells. J Nutr 132:693-696

Mazur A, Feillet-Coudray C, Romier B, Bayle D, Gueux E, Ruivard M, Coudray C, Rayssiguier Y (2003) Dietary iron regulates hepatic hepcidin 1 and 2 mRNAs in mice. Metabolism 52:1229-1231

Mena NP, Esparza A, Tapia V, Valdes P, Nunez MT (2008) Hepcidin inhibits apical iron uptake in intestinal cells. Am J Physiol Gastrointest Liver Physiol 294:G192-G198. doi:10.1152/ajpgi. 00122.2007

Menotti E, Henderson BR, Kuhn LC (1998) Translational regulation of mRNAs with distinct IRE sequences by iron regulatory proteins 1 and 2. J Biol Chem 273:1821-1824

Millard KN, Frazer DM, Wilkins SJ, Anderson GJ (2004) Changes in the expression of intestinal iron transport and hepatic regulatory molecules explain the enhanced iron absorption associated with pregnancy in the rat Gut 53:655-660

Nemeth E, Rivera S, Gabayan V, Keller C, Taudorf S, Pedersen BK, Ganz T (2004a) IL-6 mediates hypoferremia of inflammation by inducing the synthesis of the iron regulatory hormone hepcidin. $\mathrm{J}$ Clin Invest 113:1271-1276

Nemeth E, Tuttle MS, Powelson J, Vaughn MB, Donovan A, Ward DM, Ganz T, Kaplan J (2004b) Hepcidin regulates cellular iron efflux by binding to ferroportin and inducing its internalization. Science 306:2090-2093

Nicolas G, Chauvet C, Viatte L, Danan JL, Bigard X, Devaux I, Beaumont C, Kahn A, Vaulont S (2002) The gene encoding the iron regulatory peptide hepcidin is regulated by anemia, hypoxia, and inflammation. J Clin Invest 110:1037-1044

Nunez MT, Tapia V, Arredondo M (1996) Intestinal epithelia (Caco2) cells acquire iron through the basolateral endocytosis of transferrin. J Nutr 126:2151-2158

Nunez MT, Tapia V, Rojas A, Aguirre P, Gomez F, Nualart F (2010) Iron supply determines apical/basolateral membrane distribution of intestinal iron transporters DMT1 and ferroportin 1. Am J Physiol Cell Physiol 298:C477-C485. doi:10.1152/ajpcell. 00168.2009

Pantopoulos K (2004) Iron metabolism and the IRE/IRP regulatory system: an update. Ann N Y Acad Sci 1012:1-13

Pinto $M$ et al (1983) Enterocyte-like diferentiation and polarization of the human colon carcinoma cell line Caco-2 in culture. Biol Cell 47:323-330

Quintanar-Audelo M, Yusoff P, Sinniah S, Chandramouli S, Guy GR (2011) Sprouty-related Ena/vasodilator-stimulated phosphoprotein homology 1-domain-containing protein (SPRED1), a tyrosine-protein phosphatase non-receptor type 11 (SHP2) substrate in the Ras/extracellular signal-regulated kinase (ERK) pathway. J Biol Chem 286:23102-23112. doi:10.1074/jbc.M110. 212662

Radonic A, Thulke S, Mackay IM, Landt O, Siegert W, Nitsche A (2004) Guideline to reference gene selection for quantitative real-time PCR. Biochem Biophys Res Commun 313:856-862

Resta-Lenert S, Das S, Batra SK, Ho SB (2011) Muc17 protects intestinal epithelial cells from enteroinvasive $E$. coli infection by promoting epithelial barrier integrity. Am J Physiol Gastrointest Liver Physiol 300:G1144-G1155. doi:10.1152/ajpgi.00138.2010
Roy CN, Enns CA (2000) Iron homeostasis: new tales from the crypt. Blood 96:4020-4027

Sambuy Y, De Angelis I, Ranaldi G, Scarino ML, Stammati A, Zucco F (2005) The Caco- 2 cell line as a model of the intestinal barrier: influence of cell and culture-related factors on Caco- 2 cell functional characteristics. Cell Biol Toxicol 21:1-26. doi:10. 1007/s10565-005-0085-6

Sharp P, Tandy S, Yamaji S, Tennant J, Williams M, Singh Srai SK (2002) Rapid regulation of divalent metal transporter (DMT1) protein but not mRNA expression by non-haem iron in human intestinal Caco-2 cells. FEBS Lett 510:71-76

Smyth GK (2004) Linear models and empirical bayes methods for assessing differential expression in microarray experiments. Stat Appl Genet Mol Biol. doi:10.2202/1544-6115.1027

Tallkvist J, Bowlus CL, Lonnerdal B (2000) Functional and molecular responses of human intestinal Caco- 2 cells to iron treatment. Am J Clin Nutr 72:770-775

Tallkvist J, Bowlus CL, Lonnerdal B (2001) DMT1 gene expression and cadmium absorption in human absorptive enterocytes. Toxicol Lett 122:171-177

Tallkvist J, Bowlus CL, Lonnerdal B (2003) Effect of iron treatment on nickel absorption and gene expression of the divalent metal transporter (DMT1) by human intestinal Caco-2 cells. Pharmacol Toxicol 92:121-124

Tandy S, Williams M, Leggett A, Lopez-Jimenez M, Dedes M, Ramesh B, Srai SK, Sharp P (2000) Nramp2 expression is associated with $\mathrm{pH}$-dependent iron uptake across the apical membrane of human intestinal Caco-2 cells. J Biol Chem 275:1023-1029

Tremblay E et al (2006) Gene expression profiles of normal proliferating and differentiating human intestinal epithelial cells: a comparison with the Caco-2 cell model. J Cell Biochem 99:1175-1186. doi: $10.1002 /$ jcb. 21015

Vulpe CD, Kuo YM, Murphy TL, Cowley L, Askwith C, Libina N, Gitschier J, Anderson GJ (1999) Hephaestin, a ceruloplasmin homologue implicated in intestinal iron transport, is defective in the sla mouse. Nat Genet 21:195-199. doi:10.1038/5979

Waheed A, Grubb JH, Zhou XY, Tomatsu S, Fleming RE, Costaldi ME, Britton RS, Bacon BR, Sly WS (2002) Regulation of transferrin-mediated iron uptake by HFE, the protein defective in hereditary hemochromatosis. Proc Natl Acad Sci USA 99:3117-3122. doi:10.1073/pnas.042701499

Yamaji S, Sharp P, Ramesh B, Srai SK (2004) Inhibition of iron transport across human intestinal epithelial cells by hepcidin. Blood 104:2178-2180. doi:10.1182/blood-2004-03-0829

Zhang DL, Hughes RM, Ollivierre-Wilson H, Ghosh MC, Rouault TA (2009) A ferroportin transcript that lacks an iron-responsive element enables duodenal and erythroid precursor cells to evade translational repression. Cell Metab 9:461-473. doi:10.1016/j. cmet.2009.03.006

Zoller H, Theurl I, Koch R, Kaser A, Weiss G (2002) Mechanisms of iron mediated regulation of the duodenal iron transporters divalent metal transporter 1 and ferroportin 1. Blood Cells Mol Dis 29:488-497

Zucco F et al (2005) An inter-laboratory study to evaluate the effects of medium composition on the differentiation and barrier function of Caco-2 cell lines. Altern Lab Anim ATLA 33:603-618 